\title{
Toz Enjeksiyon Kalıplamada Iç Vida Profilinin Maça Kullanmadan Elde Edilmesinin Araştırılması
}

\author{
Mehmet Subaşı \\ Teknik Bilimler Meslek Yüksek Okulu, Makine ve Metal Teknolojileri Bölümü, Gazi Üniversitesi, Türkiye \\ Orcid ID: 0000-0003-4826-9175
}

\section{Özet}

Toz enjeksiyon kalıplama (TEK) metal ve seramik tozlarından karmaşık şekilli küçük hacimli parçaların kitlesel üretilmelerinde kullanılan bir tekniktir. Bu yöntem besleme stoku hazırlama, kalıplama, bağlayıcı giderme ve sinterleme aşamalarından meydana gelmektedir. TEK deki kalıplama aşaması plastik enjeksiyon kalıplama yöntemine benzer. Bu çalışma da parça içerisindeki vida geometrisinin insörtlü ve insörtsüz elde edilebilirliği araştırılmıştır. Çalışmada ilk olarak 316L besleme stoku kalıp içerisine enjekte edilmiştir. Kalıptan çıkan ham numunelerin bir kısmı 3,3 mm çapında delinmiş ve daha sonra M4 kılavuz çekilmiştir. Diğer bir kısmına ise delme işleminden sonra çekme oranı (\%16) kadar büyük imal edilmiş M4 kılavuz çekilmiştir. Standart M4 kılavuz çekilmiş numunelerin içerisine insörtler konulmuştur diğerlerine konulmamıştır. Bu insörtler de yüksek sıcaklığa dayanıklı boya ile kaplanmıştır. Hazırlanan numuneler iki farklı sinterleme sıcaklığı $\left(1260{ }^{\circ} \mathrm{C}-1340\right.$ $\left.{ }^{\circ} \mathrm{C}\right)$ ve süresin de (30-90 dakika) sinterlenmiştir. Deneyler sonucunda vidalı insört üzerindeki boya ara katmanın kusursuz diş geometrisinin elde edilmesinde yeterli olmadığı belirlenmiştir. Çekme oranı kadar büyük imal edilmiş M4 kılavuz çekilmiş numunelerde ise diş profilinin elde edilebildiği belirlenmiştir.

Anahtar kelimeler : 316L besleme soku, Toz enjeksiyon kalıplama, ara katman, kılavuz çekme

\section{Investigation of Obtaining Inner Screw Profile Without Cores in Powder Injection Molding}

\author{
Mehmet Subaşı \\ Technical Sciences Vocational School of Higher Education, Department of Machine and Metal Technology Gazi \\ University, TURKEY Orcid ID: 0000-0003-4826-9175
}

\begin{abstract}
Powder injection molding (PIM) is a technique used in the mass production of small volume parts with complex shapes from metal and ceramic powders. This method consists of feedstock preparation, molding, debinding, and sintering steps. The molding step in PIM is similar to the plastic injection molding method. In this study, the manufacturability of screw geometry was investigated with insert and without the insert. Firstly, 316L feedstock was injected into the mold in the study. Some of the molded samples were drilled in diameter $3.3 \mathrm{~mm}$ and then tapped with standard $\mathrm{M} 4$ tap. The other sample was tapped with M4, which was manufactured as large as the shrinkage ratio (16\%). Inserts are placed into the standard M4 tapped samples and into others not. Placed inserts are also coated with hightemperature resistant paint. The prepared samples were sintered at two different sintering temperatures $\left(1260^{\circ} \mathrm{C}-1340^{\circ} \mathrm{C}\right)$ and time (30-90 minutes). As a result of the experiments, it was determined that the paint interlayer on the screw insert was not sufficient to obtain the perfect tooth geometry. It was determined that the thread profile could be obtained in M4 tapped samples manufactured as large as the shrinkage ratio.
\end{abstract}

Key words: $316 \mathrm{~L}$ feedstock, Powder injection molding, interlayer, tapped

*Corresponding author: Address: Technical Sciences Vocational School of Higher Education, Department of Machine and Metal Technology Gazi University, 06374, Ankara TURKEY. E-mail address: msubasi@gazi.edu.tr, Tel: +903123548401 


\section{Giriş}

Toz enjeksiyon kalıplama (TEK) yöntemin de ilk olarak besleme stoku hazırlanır, daha sonra besleme stoku kalıp içerisine enjekte edilir. Enjeksiyon işleminden sonra kalıptan çıkan numuneler bağlayıcı giderme ve sinterleme işlemlerine tabii tutulurlar. TEK deki kalıplama süreci plastik enjeksiyon kalıplama yöntemine benzer özellikler taşır. TEK yönteminde de parça üzerindeki geometriler hareketli ve hareketsiz maça sistemleri ile elde edilirler. Parça içerisindeki vida geometrisinin elde edilmesinde hareketli maça sistemine ihtiyaç vardır.

İmalat teknolojileri içerisinde vidalı bağlantı sistemi yaygın bir şekilde kullanılmaktadır. Vidalı bağlantının tercih edilme sebeplerinden en önemlisi vida geometrisine sahip elemanların hızlı bir şekilde sökülüp takılabilmesidir. Silindirik iç ve diş yüzeyler üzerine açılan helisel girinti ve çıkıntılara vida denir. Vida geometrisinin parçaların içerisine açılmasında kılavuzlar yaygın bir şekilde kullanılmaktadır [1].

TEK in sinterleme aşamasında, parçanın içerisine yerleştirilen insört ile besleme stoku bölgesi difüzyon kaynağı prensiplerine bağlı olarak birleşmektedir. Böylece, TEK yöntemi ile parça üretimindeki boyut sınırlaması giderilmiştir [2]. İnsört ile besleme stoku arasındaki difüzyon mekanizmasının güçlendirilmesi için ara katman kullanımı yaygın bir yöntemdir. Bu çalışmada ise ara katman difüzyon mekanizmasını engellemek amacı ile kullanılmıştır.

Yılmaz ve arkadaşları [3] TEK yöntemi ile kendinden montajlı ve hareketli parça üretimini araştırmışlardır. Montajlanacak bileşenler arasındaki boşluk ile sistemin hareket etmesi sağlamışlardır. Bileşenler arasındaki boşluğun ise krom katmanı ile elde edilebileceğini belirlemişlerdir.

Urtekin ve arkadaşları [4] TEK yöntemi ile Ti-6Al-4V den kemik vida implantının imalatını araştırmışlardır. Deneyler sonucunda kemik vida implatının kusursuz bir şekilde elde edilebilmesi için gerekli optimum kalıplama ve sinterleme parametrelerini belirlemişlerdir.

Koçak ve arkadaşları [5] insörtlü toz enjeksiyon kalıplama yöntemi ile WC parça üretiminde ara katmanın etkisini incelemişlerdir. Deneyler sonucunda büyük hacimli WC parça elde etmek için nikel ara katmanın gerekli olduğunu belirlemişlerdir.

Literatürde yapılan çalışmalarda parçada bulunan diş profilinin elde edilmesinde kalıp üzerindeki maça sistemlerinden yararlanıldığı belirlenmiştir. Bu çalışama da maça sistemi kullanmaksızın vida profilinin elde edilmesi araştırılmıştır. Deneyler de numuneler insörtlü ve insörtsüz olmak üzere iki ana bölüme ayrılmıştır. Numunelerin bir kısmının içlerine ısıya karşı dayanıklı boya ile kaplanmış insörtler yerleştirilmiştir. Diğer kısmına ise çekme payı kadar büyük yapılmış M4 kılavuz ile diş profilleri oluşturulmuştur. Sinterleme deneyleri sonucu parçalardaki diş profili durumu incelenmiştir. 


\section{Materials and Method}

Parçanın sinterlenmesi esnasında parçanın iç kısmında vida geometrisinin elde edilmesi için insörtler kullanılmıştır. İnsört olarak AISI 1050 çeliğinden hazırlanmış boya kaplı M4 saplama (Tij) kullanılmıştır (Şekil 1).

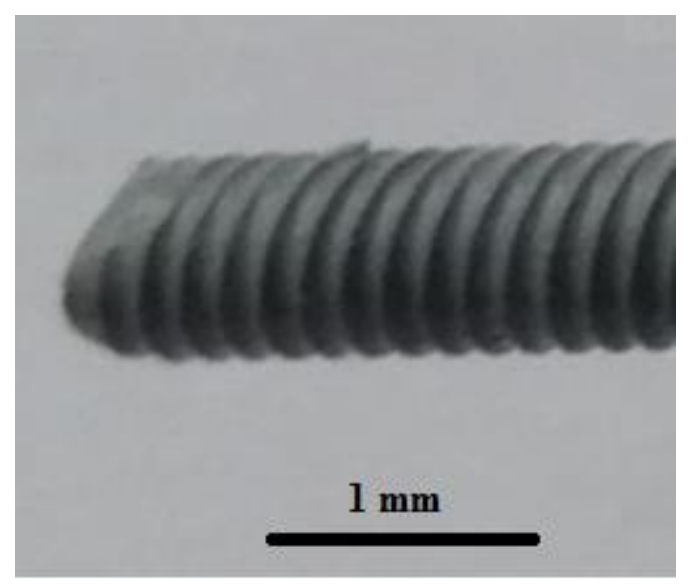

Şekil 1. Isıya karşı dayanıklı boya ile kaplanmış M4 saplama

Toz enjeksiyon kalıplama da insört üzerine besleme stoku enjekte edildikten sonra parçalar bağlayıcı giderme ve sinterleme işlemlerine tabi tutulursa insört ile besleme stoku bölgesi arasında bir difüzyon meydana gelmektedir. Bu çalışmada insört ile vida profili elde etmek ve besleme stoku bölgesi ile insört arasındaki difüzyonu engellemek için insörtler üzerinde bir ara katman oluşturulmuştur. İnsörtler üzerinde ara katman oluşturmak için su bazlı ve akrilik esaslı boya kullanılmıştır. İnsörtlerin kaplanmasında kullanılan boyanın kaybolma sıcaklığ $600{ }^{\circ} \mathrm{C}$ civarındadır. Bu özelliklere sahip boya ile insörtler üzerinde 5-7 $\mu \mathrm{m}$ kalınlığında ara katman oluşturulmuştur.

Deney numunelerinin hazırlanmasında kullanılan 316L besleme stoku Almanya da bulunan eMBe (eMBe Products and Service GmbH, Thierhaupten, Germany) firmasından temin edilmiştir. 316L besleme stokunun kimyasal bileşimi Tablo 1 de, besleme stoku içerisindeki tozların özellikleri Tablo 2 de verilmiştir.

Tablo 1. 316L besleme stokunun kimyasal özellikleri 


\begin{tabular}{|c|c|c|c|c|c|c|c|}
\hline $\mathrm{C}(\%)$ & $\mathrm{P}(\%)$ & $\mathrm{Cr}(\%)$ & $\mathrm{Ni}(\%)$ & $\mathrm{Mo}(\%)$ & $\mathrm{Mn}(\%)$ & $\mathrm{Si}(\%)$ & $\mathrm{Fe}$ \\
\hline 0,03 & 0,045 & $16-18$ & $12-15$ & $2-3$ & $<2$ & $\leq 1,0$ & $\begin{array}{c}\text { Geri } \\
\text { kalan }\end{array}$ \\
\hline
\end{tabular}

Tablo 2. Besleme stokunda kullanılan tozun özellikleri

\begin{tabular}{|c|c|c|}
\hline Üretim yöntemi & Boyut & $\begin{array}{c}\text { Toz yükleme oran1 } \\
\text { (ă̆grlıkça \%) }\end{array}$ \\
\hline Su atomizasyon & $\begin{array}{c}\mathrm{D}_{50}: 7 \mu \mathrm{m}, \\
\mathrm{D}_{90}: 13 \mu \mathrm{m}\end{array}$ & $\% 92,5-93,1$ \\
\hline
\end{tabular}

\subsection{Toz enjeksiyon kalıplama, bağlayıcı giderme ve sinterleme işlemi}

Şekil 2 de çalışmada kullanılan TEK yönteminin aşamaları verilmiştir.

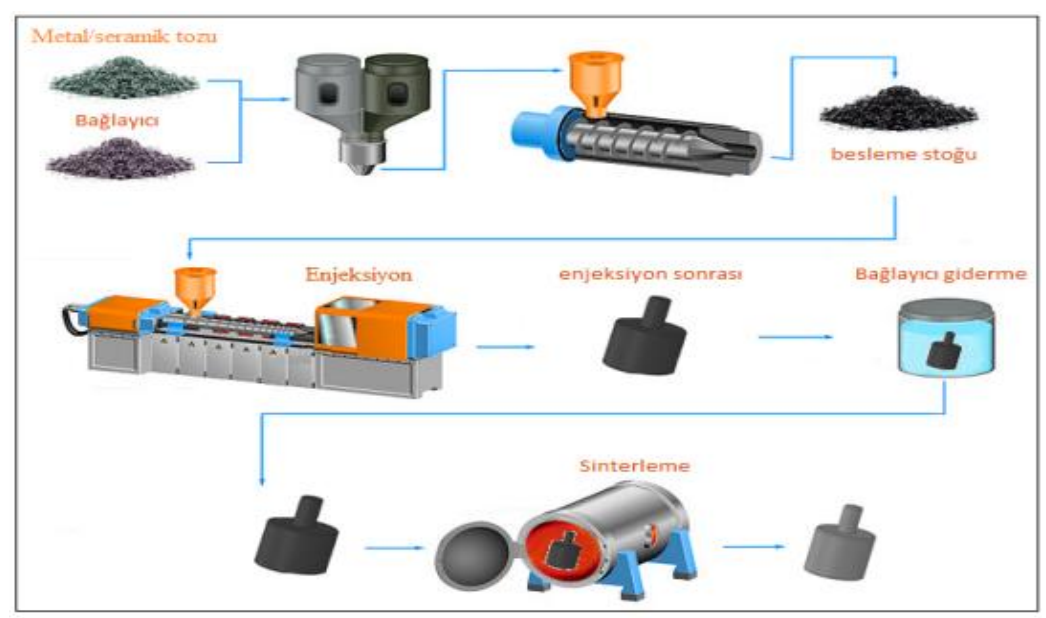

Şekil 2. TEK yönteminin aşamaları [6]

Deney numuneleri toz enjeksiyon kalıplama işleminden sonra bağlayıcı giderme ve sinterlemeye tabi tutulmuşlardır (Şekil 3). Toz enjeksiyon kalıplama parametreleri Tablo 3 de verilmiş̧ir. Bağlayıcı giderme işlemi $60{ }^{\circ} \mathrm{C}$ sıcaklıkta etanol çözeltisinde 24 saat bekletilerek gerçekleştirilmiştir. Numunelerin sinterleme işlemi atmosfer kontrollü tüp firın içerinde yapılmıştır. Numuneler $1260^{\circ} \mathrm{C}-1340^{\circ} \mathrm{C}$ sinterleme sicaklıklarında ve 30 ve 90 dakika sürelerde sinterlenmişlerdir. Sinterleme deneyleri $4,5^{\circ} \mathrm{C} /$ dakika ssıtma, $5{ }^{\circ} \mathrm{C}$ / dakika soğutma hızlarında ve $95 \% \mathrm{~N}_{2}+5 \% \mathrm{H}_{2}$ karışım gaz atmosferinde yapılmıştır. 

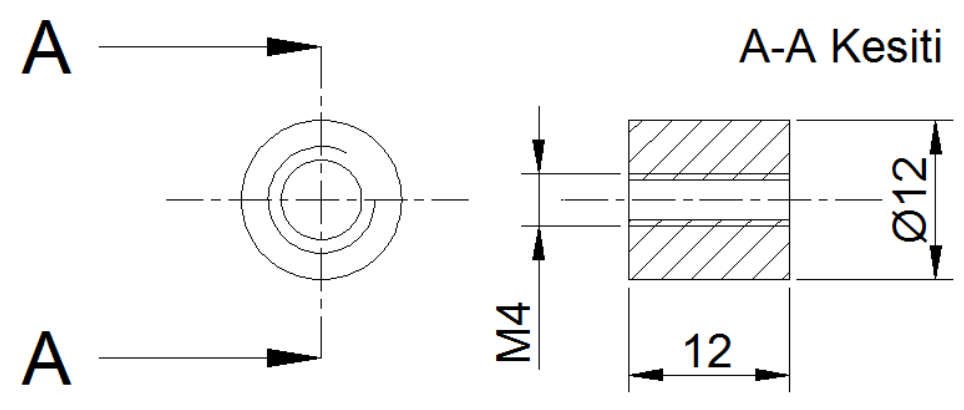

Şekil 3. Toz enjeksiyon kalıplamada hazırlanan ham numuneler

Tablo 3. Toz enjeksiyon kalıplama parametreleri

\begin{tabular}{|c|c|c|c|c|c|c|}
\hline $\begin{array}{c}\text { Enjeksiyon } \\
\text { hızı }\left(\mathrm{cm}^{3} / \mathrm{s}\right)\end{array}$ & $\begin{array}{c}\text { Enjeksiyon } \\
\text { basınc1 (bar) }\end{array}$ & $\begin{array}{c}\text { Enjeksiyon } \\
\text { süresi } \quad(\mathrm{s})\end{array}$ & $\begin{array}{c}\text { Ütüleme } \\
\text { basıncı (bar) }\end{array}$ & $\begin{array}{c}\text { Enjeksiyon } \\
\text { sıaklığ }\left({ }^{\circ} \mathrm{C}\right)\end{array}$ & $\begin{array}{c}\text { Kalıp } \\
\text { sicaklığ1 }\left({ }^{\circ} \mathrm{C}\right)\end{array}$ & $\begin{array}{c}\text { Soğutma } \\
\text { süresi }\end{array}$ \\
\hline 1 & 120 & 3 & 50 & 150 & 45 & 5 \\
\hline
\end{tabular}

\section{Sonuçlar ve Tartışma}

Tablo 3 de belirtilen enjeksiyon parametrelerinde deney numuneleri hazırlanmıştır. Toz enjeksiyon işleminden sonra bir kısım numunelere standart M4 kılavuz çekilmiştir (Şekil 4).

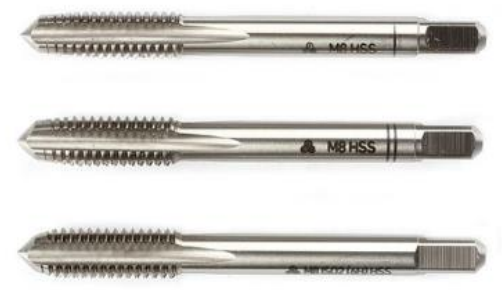

Şekil 4. Standart M4 kılavuz takımı

Standart kılavuz çekilmiş numunelerin içerisine boya ara katmanlı insörtler yerleştirilmiştir (Şekil 1). Boya ara katmanı ile insört ile besleme stoku bölgesi arasında oluşması muhtemel olan difüzyon 
engellenmeye çalışılmıştır. İçerisine insört yerleştirilmiş ve yerleştirilmemiş numuneler $1260{ }^{\circ} \mathrm{C}$ ve $1340^{\circ} \mathrm{C}$ sıcaklıklar da 30 ila 90 dakika sürelerde sinterlenmişlerdir. Sinterleme işleminden sonra numunelerin içerisindeki vida geometrili insörtler ile besleme stoku bölgesinin birbirlerine difüzyon olduğu belirlenmiştir. İnsört ile besleme stoku bölgelerinin birbirlerine difüzyon olduğu numuneler kesilerek vida profilleri incelenmiştir (Şekil 5).

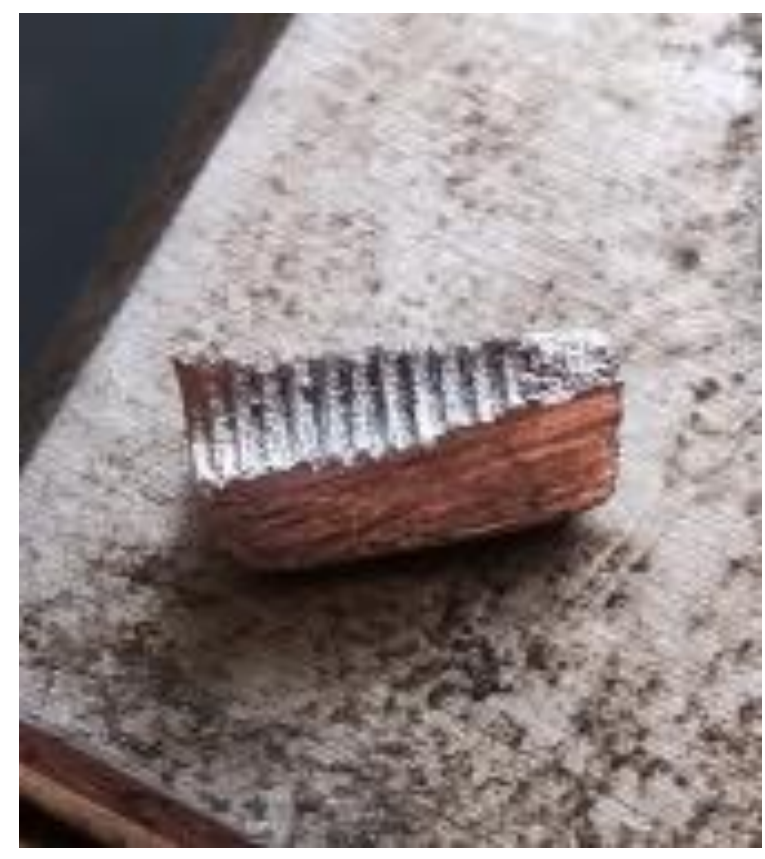

Şekil 5. İnsörtlü sinterlenmiş numune

Optik mikroskop görüntülerinde standart M4 kılavuz çekilen ve boya ara katmanlı insört ile birlikte sinterlenen numunelerin diş profillerin de bozulmalar olduğu belirlenmiştir (Şekil 6). Bu durumun sebebi olarak ara katmanlı insörtlerin parçalara takılması esnasında enjeksiyondan çıkan ham parçalardaki vida profillerine zarar vermesinden dolayı olduğu düşünülmektedir. 


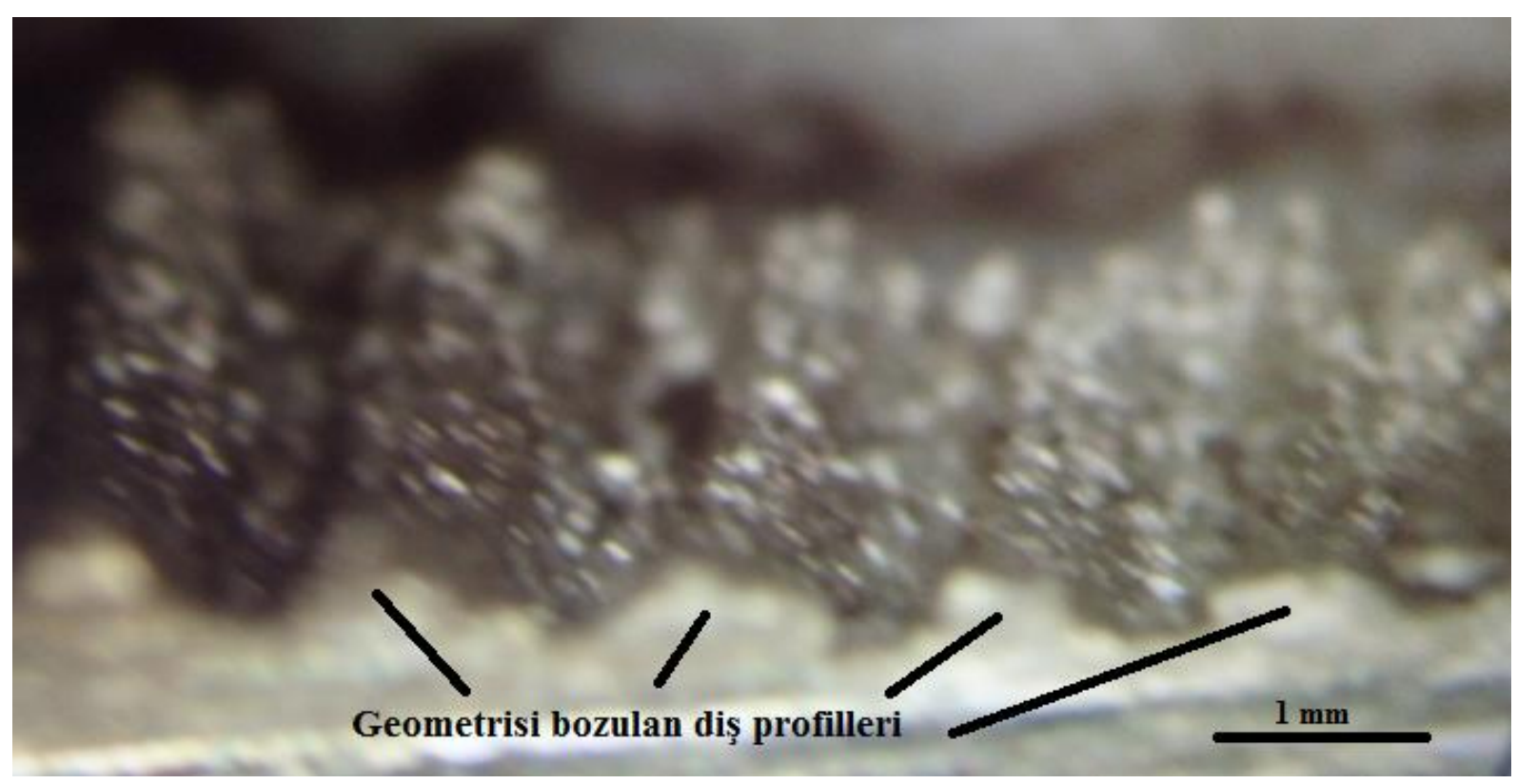

Şekil 6. Diş profili bozulan numune

Çalışmanın ikinci grubundaki numunelere ise çekme payı kadar (\%16) büyük yapılan M4 kılavuz salınmıştır. Bu numuneler insörtsüz olarak sinterlenmişlerdir. Sinterleme işleminden sonra standard M4 bir saplama numunelere problemsiz bir şekilde takılabilmiştir.

\section{Sonuçlar}

TEK yöntemi ile parça içerisindeki vida geometrisinin insörtlü ve insörtsüz olarak elde edilmesinin araştırıldığı bu çalışmada elde edilen sonuçlar şunlardır;

- İnsört üzerindeki boya ara katmanının besleme stoku bölgesi ile insört arasındaki difüzyonu engellemediği belirlenmiş̦tir.

- Boya ara katmanlı insörtlerin ham parçaya yerleştirilmesi aşamasında parça içerisindeki vida geometrisini bozduğu belirlenmiştir.

- TEK yöntemi ile iç vida geometrisinin elde edilmesinde çekme oranı kadar büyük yapılan kılavuzun iç vida geometrisi elde etmede olumlu sonuçlar verdiği belirlenmiştir.

\section{Teşekkür}

Bu çalışma TUBİTAK (113M125) ve Gazi Üniversitesi BAP birimi (07 / 2013-03) tarafından desteklenmiştir. 


\section{References}

[1] Uzun G. Ti6Al4V titanyum alaşımında kılavuz ile vida açma problemlerinin araştırılması. Doktora Tezi, Gazi Üniversitesi, Fen Bilimleri Enstitüsü, 2013.

[2] Safarian A, Subaşı M, Karataş Ç. The effect of sintering parameters on diffusion bonding of 316 L stainless steel in inserted metal injection molding. Int J Adv Manuf Technol. 2017; 89:2165-2173.

[3] Yılmaz O, Samet K, Koçak H, Karataş Ç. Toz enjeksiyon kalıplamada krom arayüzeyi kullanılarak montajılı parça imalatının araştırılması. Journal of the Faculty of Engineering and Architecture of Gazi University 2019; 34(2): 621-634.

[4] Urtekin L, Taskin A. Ti-6Al-4V alloy cortical bone screw production by powder injection molding method. Materials Express 2017; 7(4): 245-252.

[5] Koçak H, Subaşı M, Karataş Ç. Sinter bonding of AISI 4340 and WC-Co using Ni interlayer by inserted powder injection molding. Ceramics International 2019; 45: 22331-22335.

[6] Koçak H. Farklı insört malzemeler kullanılarak toz enjeksiyon yöntemiyle kesici takım üretiminin araştırılması. Doktora Tezi, Gazi Üniversitesi, Fen Bilimleri Enstitüsü, 2018. 